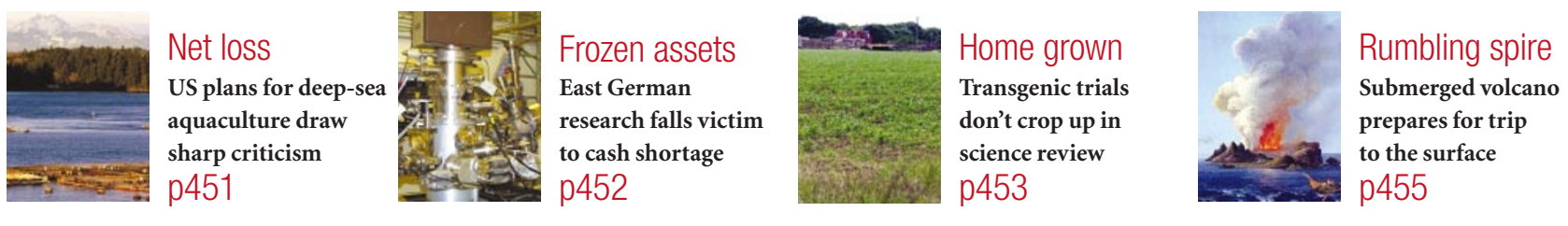

\title{
Surgeons struggle with ethical nightmare of face transplants
}

\section{Natasha McDowell, London}

Transplant experts are this week coming to terms with claims by a top London surgeon that face transplants could soon move from the realm of Hollywood fantasy into actual clinical practice.

The technology needed to perform a face transplant could be ready within six months, Peter Butler of the Royal Free Hospital told the winter meeting of the British Association of Plastic Surgeons in London on 27 November.

"The science is a small part. The question is not can we do it, but should we do it," Butler said. He added that hand transplants have already provided proof of principle that composite tissues of skin, blood and bone can survive transplantation with the help of modern immunosuppressive drugs. Such drugs suppress the recipient's immune system and so prevent the grafted tissue from being rejected by the patient's body.

For many, the claim may bring to mind the face- and identity-swapping escapades of John Travolta and Nicholas Cage in the 1997 movie Face/Off. But in real life, the transplant issue will arise for people who suffer from disfigurements that are so severe as to make the drastic surgery a viable consideration.

Some of these people find Butler's statements unhelpful. "It is a speculative idea, but has gained huge media attention that may have been damaging to individuals trying to adjust to their disfigurement," says burns victim James Partridge, founder and chief executive of the London-based charity Changing Faces, which helps those with facial disfigurement. "It should have been opened as a private debate between psychologists and surgeons before being made public." Partridge says that he has not met anyone who is interested in undergoing a face transplant. "Even for those like myself with severe disfigurement, the face carries a lot of identity, the sense of self," he says.

But Christine Piff, founder of the UK support group Let's Face It, says the technology could benefit those whose disfigurement is so severe that they become withdrawn, or those who cannot eat, drink or speak. She herself lost half of her face to cancer 25 years ago, and

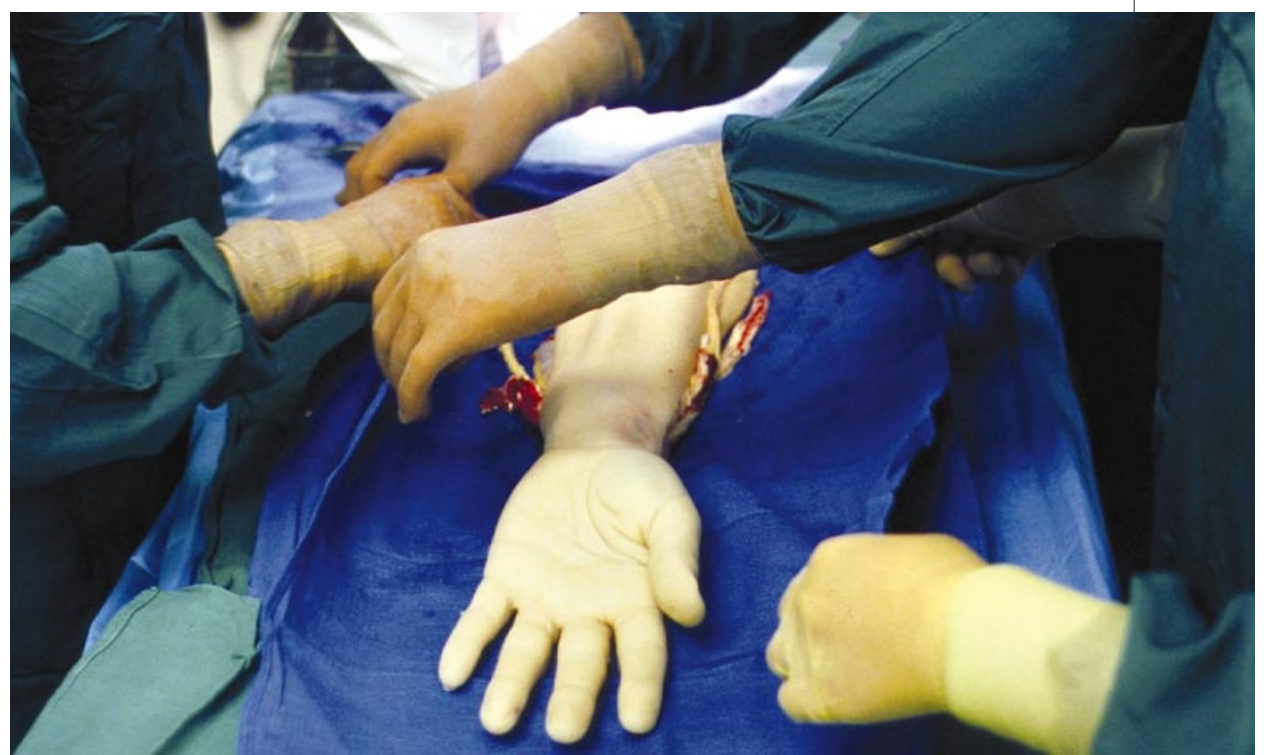

Hand up: hand transplants have already shown that tissue composites can survive transplantation.

adds that although she would probably have refused a transplant at the time, when she reflects on the advantages it might have offered, she is now not so sure.

Butler says that although the ultimate aim is to transplant bone and muscle, his team's initial approach will be to transplant only skin, subcutaneous tissue and blood vessels. This would leave patients with their own recognizable features, but with potentially more flexibility than is currently available with a graft of a patient's own non-facial skin.

Critics say that practical use of the approach is further off than Butler suggests. "Technically, face transplants could be done this afternoon," says John Clarke, a plastic surgeon and director of the burns unit at Chelsea and Westminster Hospital in London. "The big problem will be finding donors, and the psychological difficulties could be dreadful."

Any patient who received the transplant would have to take immunosuppressive drugs, with their increased risk of cancer and infection, for the rest of his or her life. For this reason, the treatment would only be ethically acceptable either for patients who are so disfigured that they become suicidal, or for those who already have life-threatening facial cancer. But immunosuppressive drugs do not always prevent rejection, and could hinder the patient's ability to combat the cancer, says Jim Frame, a plastic reconstructive surgeon who has spent 20 years working on the possibility of face transplants. He now thinks that more promising approaches will come from the use of man-made materials to restore patients' facial features.

However, Butler's hope is that immune rejection may eventually be overcome by an approach being developed at Massachusetts General Hospital in Boston. This involves first grafting bone marrow from a donor while treating the patient with immunosuppressives. Work on animals suggests this can induce immune tolerance in the recipient, allowing a further transplant from the same donor without risk of rejection.

But this approach is currently aimed at those with bone-marrow cancer who are at risk of accompanying organ failure, says Steve Schey, director of the stem-cell transplant unit at Guy's Hospital, London. He says the approach is interesting, but speculative. 